\title{
Stability Analysis of Power System in a 33/11kv Distribution Network
}

\author{
${ }^{1}$ Anyaka Boniface Onyemaechi, ${ }^{2}$ Orji Ude Odim \\ ${ }^{1,2}$ Department Of Electrical Engineering University Of Nigeria, Nsukka Enugu State, Nigeria
}

\begin{abstract}
A study here was made of the accuracy of utility power system stability simulations, as affected by the complexity of the synchronous generator models and data used with the models. The investigation was performed by simulating the operation of a representative multi-machine system with many combinations of disturbances, initial load, system stiffness, model detail and model data by the use of MATLAB. The findings from this research work provide guidelines in the selection of the parameter in the power system designs and operations.
\end{abstract}

Keywords: stability,Power,Transient,Distribution,Synchronism.

\section{Introduction}

Stability considerations have been recognized as essential part of power system planning for a very long time. The period of interest is the transient period before a new steady-state condition is reached. Some groups published fundamental papers on the subject in the transaction years ago [1]. Within a few years, stability studies of new generation and transmission facilities had become a routine. Over most of the history of power system growth in the world, acceptable stability performance has been achieved without difficulty. Approximately, within the last three decades, however, changes have occurred which require power system engineers to devote much more of their effort to this problem.

Depending on individual experience and viewpoint, there are no doubt various explanation for the increased concern with stability. The underlying cause, however would appear to be the very extensive interconnection of power systems with great dependence on firm power over ties. This magnifies the undesirable consequences of instability and complicates the analytical processes through which acceptable system behavior is assured. Fortunately, the digital computer has given engineer the ability to predict where complexity would have been too great before planting any power station. The stability problem and its calculations will be the specific example used here. Although, this determination of power stability through MATLAB has stimulated varying degrees of interest over the years, it is currently enjoying new popularity, because not only systems are more massive but also because there is now possibility of obtaining accurate answers to system response [2]. The primary motivation for the use of MATLAB in power system is to obtain the economic benefits of new large-scale generation and transmission facilities. MATLAB can also improve reliability through mutual support on the relaying systems in emergencies.

However, improved reliability is realized only if the bulk transmission system remains intact through such emergencies. If ties between systems are not strong enough to maintain synchronism in the face of disturbances, the system breaks up and the ability to provide support to areas, which become isolated vanishes. Changes in design and operation since the invention of MATLAB assures that widespread failure will not occur again in power system even when there is disturbance surge. Even so, integrity of a bulk transmission and effective operations of power system is of primary importance.

\section{Transient Stability}

Transient stability analysis is primarily concerned with the effects of transmission-line faults on generator synchronism. During a fault, electrical power from nearby generator is reduced, perhaps drastically, while power from machines somewhat removed from the fault may be scarcely changed. The resultant differences in acceleration produce speed differences over the time interval of the fault, and it is important to clear faults quickly to limit these speed differences and the associated changes in angle differences. Clearing the faults necessarily removes one or more transmission element from services and at least temporarily weakens the transmission system. This change in transmission system also implies that the generator angle differences, which existed prior to the fault no longer, represent equilibrium conditions [6]. Transient stability study is often more than an investigation of whether the synchronous generators, following the occurrence of the disturbance, will remain in synchronism. It can be general-purpose transient analysis, in which the "quality" of the dynamic system behavior is investigated. The transient Period of primary interest is the electromechanical transient, usually lasting up to a few seconds in duration [4]. Such studies, therefore support system-operating functions, and are often conducted by engineers in system operation (operations planning groups). The purpose of the 
studies can be to check that a given system configuration and/or operating condition meets the reliability criteria, to check (or change) relay settings, and to set the parameters for special stability control devices and check their settings.

The analysis of any power system to determine its transient stability involves some mechanical properties of the machines of the system, for after every disturbance, the machines must adjust the relative angle of their rotor to meet the conditions of power transfer imposed. The problem is mechanical as well as electrical, and certain mechanical principles must be kept clearly in mind when considering the problem

\section{Steady State Stability}

The is the capability of an electric power system to maintain synchronism between machines within the system and external tie lines following a small slow disturbance (normal load fluctuations, the action of an automatic voltage regulators and turbine governors) [4]. It is the property of the power system to operate in its present state and small slow changes in system loading will produce small change in the operating point. A steady-state unstable system changes will drift off to unsynchronized operation from its operating point when subjected to a slow small increase in load [5]. In case the maximum power transfer exceeds under this condition, individual machines or group of machines will cease to operate in synchronism, violent fluctuation of the voltage will occur and the steady state limit for the system as a whole would have been reached. The steady state limit refers to the maximum flow of power possible through a particular point without the loss of stability when the

Transient stability analysis is primarily concerned with the effects of transmission-line faults on generator synchronism. During a fault, electrical power from nearby generator is reduced, perhaps drastically, while power from machines somewhat removed from the fault may be scarcely changed. The resultant differences in acceleration produce speed differences over the time interval of the fault, and it is important to clear faults quickly to limit these speed differences and the associated changes in angle differences. Clearing the faults necessarily removes one or more transmission element from services and at least temporarily weakens the transmission system. This change in transmission system also implies that the generator angle differences, which existed prior to the fault no longer, represent equilibrium conditions [6]. Transient stability study is often more than an investigation of whether the synchronous generators, following the occurrence of the disturbance, will remain in synchronism. It can be general-purpose transient analysis, in which the "quality" of the dynamic system behavior is investigated. The transient Period of primary interest is the electromechanical transient, usually lasting up to a few seconds in duration [4]. Such studies, therefore support system-operating functions, and are often conducted by engineers in system operation (operations planning groups). The purpose of the studies can be to check that a given system configuration and/or operating condition meets the reliability criteria, to check (or change) relay settings, and to set the parameters for special stability control devices and check their settings.

The analysis of any power system to determine its transient stability involves some mechanical properties of the machines of the system, for after every disturbance, the machines must adjust the relative angle of their rotor to meet the conditions of power transfer imposed. The problem is mechanical as well as electrical, and certain mechanical principles must be kept clearly in mind when considering the problem.

Usually, transient stability studies are carried out over a relatively short period that will be equal to the time of one swing. Normally, the time will be one second or less. The analysis is carried out to determine whether the system loses stability during first swing or not. In case the power systems remain stable, it is assumed that subsequent swings will diminish and that power system will remain stable as usually happens. However, there is a possibility of power system going unstable in some subsequent swing. For example, negative damping is one cause. Control equipment improperly adjusted or applied can produce negative damping.

In practice, load is not applied gradually and the machine (motor or generator) is not in a position to meet the demand instantly. The limit of the system to meet such load is obviously less than steady-state stability.

As said earlier, the power systems have rotating synchronous machines, in order to know whether the system is stable or not. It is necessary to derive swing equation.

Let angular displacement $1=\theta$ radians.

\section{Swing Equation}

Angular velocity, $\mathrm{w}=\partial \underline{\theta} \mathrm{radians} / \mathrm{seconds}$

$\partial \mathrm{t}$

Angular acceleration $\gamma_{-}=\underline{\partial^{2} \theta}$ radians $/ \mathrm{second}^{2}$

$\partial \mathrm{t}^{2}$

Power developed, $\mathrm{p}=\mathrm{Tw}$ watts

Where $\mathrm{T}=$ torque in $\mathrm{N}-\mathrm{M}$ 
Angular momentum, $\mathrm{M}=\mathrm{Iw} \mathrm{J}-\mathrm{s} / \mathrm{radians}$

Where I is moment of inertia in $\mathrm{kg}-\mathrm{m}^{2}$.

In case of where the torque caused by friction, windage and core loss in a machine is disregarded, any difference between the shaft torque and electromagnetic torque developed must cause acceleration or deceleration of the machine. If $T s$ represents the shaft torque, $T_{e}$ is electromagnetic torque, and if these values of torque are considered positive for a generator (that is, with mechanical input on shaft and electric output torque developed, the torque causing acceleration is $T_{a}=T_{s}-T_{e}$

Torque due to rotational losses is assumed negligible in either case during the discussions.

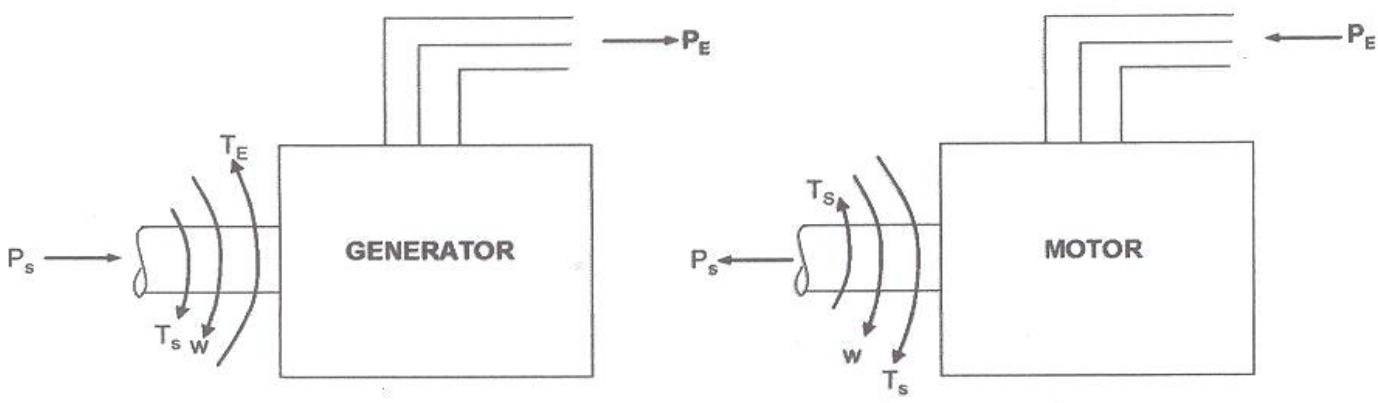

Fig.1: Flow of electrical and mechanical powers in a generator and motor

$T_{a}$ is positive denoting net torque causing acceleration of the rotor and will be positive if $T_{s}>T_{e}$. This expression holds true for motor also.

A similar relationship holds well when expressed in terms of power, namely;

$$
P_{a}=p_{s}-P_{e} \quad(2.12 .2)
$$

Where $\mathrm{P}_{\mathrm{a}}$ is the acceleration power, $\mathrm{P}_{\mathrm{s}}$ is the shaft power and $\mathrm{P}_{\mathrm{e}}$ is the electric power developed for the generator. For a motor $\mathrm{P}_{\mathrm{e}}$ is the negative of the difference between the electric power input and electric losses of the motor, that is $\mathrm{P}_{\mathrm{e}}$ is negative of the electric power developed. If rotational losses (friction, windage, and core losses including eddy-current losses in the damping winding are considered, $\mathrm{P}_{\mathrm{S}}$ is the negative of the shaft power output plus rotational losses for a motor, and $\mathrm{P}_{\mathrm{s}}$ is the shaft power input minus rotational losses for a generator.

\section{Dynamic Stability}

The stability characteristic of large power systems is too varied to permit a simple classification of behavior, and it is not possible to separate all analyses into simple categories. Nevertheless, the term "transient stability" and "dynamic stability" are widely used to distinguish between two kinds of studies. Dynamic stability studies are usually made to determine the consequences of suddenly having a significant excess of either load or generation in an isolated power system. Such system might be normally isolated and lose load or generation, or it might normally be part of a larger system and becomes separated. Much of the effort devoted in dynamic stability analysis is concentrated on the problem associated with undamped or poorly damped oscillation [7].

A mechanical rotary system possesses inertia $J$ and a torque $M_{o}$ per radian tending to restore its position when given an angular displacement, has a natural frequency, $\mathrm{F}_{\mathrm{o}}=(1 / 2 \pi)\left(\mathrm{m}_{\mathrm{o}} / \mathrm{J}\right)$, and a corresponding natural period to $2 \pi\left(\mathrm{m}_{\mathrm{o}} / \mathrm{J}\right)$. neglecting damping, effect. A synchronous machine working in parallel with other machines forms such a system. Under steady-state conditions, it rotates at an angular velocity $\omega_{1}=2 \Pi \mathrm{F} / \mathrm{P}$ corresponding to the number of its pole-pairs and a frequency $\mathrm{F}$ of the electrical network; further, it has a constant load angle $\mathrm{F}$ between the rotating pole-axis of its stator and rotor. However, if this relative position is disturbed, a synchronizing power flows in the machine to develop a synchronizing restoring torque.

When sufficient time has elapsed at a disturbance, the governors of

the prime movers will react to increase or reduce energy input, as may be required, to re-establish a balance between energy input and existing electrical load. This usually occurs in about 1-1.5 seconds after the disturbance. The period between the times the governors begin to react, and the time that steady state equilibrium is re-established is the period when dynamic stability characteristics of a system are effective. It is possible to have transient stable but dynamically unstable conditions. Immediately after a disturbance, the machine rotor will go through the first swing (before the governors action) successfully, and then, after governor control is initiated, the oscillation will start increasing until the machine falls out of synchronism. Such action can occur if the time delay of the governor control are such that, following the sensing of necessity for increasing or reducing energy input, action is delayed sufficiently in time augment rather than diminishing the next swing. If such a condition exists, the oscillations of the machine rotor can continue to build up until the machine falls out of synchronism. 


\section{Methods Of Improving Power System Stability \\ Increasing Of System Voltage}

Transient stability is improved by raising the system voltage profile (i.e. raising $\mathrm{E}$ and $\mathrm{V}$ ). Increase in system voltage means the higher value of maximum power, $\mathrm{P}_{\max }$ that can be transferred over the lines. Since shaft power, $\mathrm{P}_{\mathrm{s}}=\mathrm{P}_{\max } \sin \delta$, therefore, for a given shaft power, initial load angle $\delta_{\mathrm{o}}$ reduces with the increase in $\mathrm{P}_{\max }$ and thereby increasing difference between the critical clearing angle and initial loading angle. Thus, machine is allowed to rotate through large angle before it reaches the critical clearing angle, which results in greater critical clearing time and the probability of maintaining stability.

\section{Rapid Reclosure}

The great majority of faults on overhead transmission lines are transitory in nature. They disappear if they de-energized for a short while in order to permit the arc to become extinguished. After the arc has become sufficiently demonized, the line may be re-energized and put back into use. Lightening is the most common cause of fault on overhead lines and most faults caused by lighting are transitory. In addition, some faults due to other causes such as swinging wires and temporary contact with foreign objects are transitory. On the other hand, a few faults on overhead lines (for example those caused by broken wires or poles) and all faults on underground cables are permanent. High-speed circuit breakers have been made to restore the system to normal operating conditions once the fault is removed. The modern circuit broken technology has made it possible for line clearing to be done as fast as in 2 cycles. On occurrence of a fault, on a transmission line, the faulted line is de-energized to suppress the arc in fault and the circuit breaker recluses after a suitable time intervals. Automatic reclosing increases the decelerating area $\mathrm{A}_{2}$ and thus helps in improving stability.

\section{Use Of Quick-Acting Automatic Voltage Regulator}

The satisfactory operation of synchronous generators of a complex power system at high power (or load) angles and during transient condition is very much dependent on the source of excitation for the generators and on the automatic voltage regulator. The power output of a generator is proportional to internal voltage E. Under fault conditions, the terminal voltage $\mathrm{V}$ faults. A quick-acting voltage regulator causes increase in $\mathrm{E}$ so that the terminal voltage $\mathrm{V}$ remains constant. A higher value of $\mathrm{E}$ means a higher generator output.

It has already been shown that the maximum value of a power angle curve is proportional to the perunit excitation. Field forcing can, therefore cause the machine to operate on a higher power angle curve thereby, allowing it to swing the through a larger angle from its original position before it reaches the critical clearance angle.

\section{Reduction In Transfer Reactance}

Transient stability can also be improved by reducing the transfer reactance. The effect of reducing the transfer reactance means increase in $\mathrm{P}_{\max }$ resulting in increase in transient stability. The line reactance can be reduced by using more lines in parallel instead of a single line. In general, more power is transferred during a fault on one of the lines. If there are two lines in parallel, than would be transferred over a single faulted line. Increasing power transfer means less available accelerating power, because the accelerating power is the difference between power input power transfers. Lower accelerating power reduces the risk of instability.

The use of bundled conductor also helps in reducing line reactance and improves stability.

\section{Turbine Fast Valving}

One reason for power instability is the excess energy supplied by the turbine during the disturbance period. Fast valuing is a means of reducing turbine mechanical input power when a limit is under acceleration due to a transmission system fault. This can be initiated by load impedance relays, acceleration transducers or by relays that recognize only severe transmission system fault. For maximum stability gains with fast valuing, the interceptor valves are rapidly shut (in 0.1 to 0.2 second) and immediately re-opened. This procedure increases the critical switching time long enough so that in most of the cases, the unit will remain stable for faults with stuck-breaker clearing time. Presently some station in USA, have been to use fast valuing schemes.

\subsubsection{High Neutral Grounding Impedance}

In systems where the stability is of prime importance, high neutral grounding impedance may be used. The grounding is effective only for unbalanced faults. Zero-sequence impedance comes into picture to restrict faults like line-to-ground. 


\section{Case Study Simulation Of A Typical Multi - Bus Power System}

The classical transient stability study is based on the application of a three - phase fault. A solid three phase fault at bus $\mathrm{k}$ in the network results in $\mathrm{V}_{\mathrm{k}}=0$.This is simulated by removing the kth row and column from the prefault bus admittance matrix. The new bus admittance matrix is reduced by eliminating all nodes except the internal generator nodes. The generator excitation voltages during the fault and post-fault nodes are assumed to remain constant. The electrical power of the ith generator in terms of the new reduced bus admittance matrix is obtained from

$$
\begin{aligned}
& { }_{\mathrm{ei}}^{\mathrm{m}}=\Sigma\left|\mathrm{E}^{\prime} \mathrm{i}\right|\left|\mathrm{E}^{\prime} \mathrm{j}\right| \mathrm{Yij} \mid \cos (\Theta \mathrm{ij}-\partial \mathrm{i}+\partial \mathrm{j}) \\
& \mathrm{j}=1
\end{aligned}
$$

The swing in question with damping neglected, for machine $\mathrm{i}$ becomes

$$
\frac{\mathrm{H}_{\mathrm{i}} \mathrm{d}^{2} \partial \mathrm{i}}{\pi \mathrm{f}_{\mathrm{o}} \partial^{\mathrm{t2}}} \underset{\mathrm{j}=1}{\mathrm{P}} \underset{\mathrm{mi}}{\mathrm{m}-\Sigma\left|\mathrm{E}^{\prime} \mathrm{i}\right|\left|\mathrm{E}^{\prime} \mathrm{j}\right| \mathrm{Yij} \mid \cos (\Theta i j-\partial \mathrm{I}+\partial \mathrm{j})}
$$

Where $Y_{i j}$ are the elements of the faulted reduced bus admittance matrix, and $\mathrm{H}_{\mathrm{i}}$ is the inertia constant of machine $\mathrm{i}$ expressed on the common MVA based $\mathrm{S}_{\mathrm{B}}$. If $\mathrm{H}_{\mathrm{Gi}}$ is the inertia constant of machine $\mathrm{i}$ expressed on the machine rated MVA $\mathrm{S}_{\mathrm{Gi}}$, then $\mathrm{H}_{\mathrm{i}}$ is given by

$$
\begin{aligned}
& \mathrm{H}_{\mathrm{i}}=\mathrm{S}_{\mathrm{Gi}} \mathrm{H}_{\mathrm{Gi}} \\
& \mathrm{S}_{\mathrm{B}}
\end{aligned}
$$

$\mathrm{S}_{\mathrm{B}}$ yields

Showing the electrical power of the ith generator by $P_{\mathrm{e}}$ and transforming 3.11 into state variable model

$$
\begin{aligned}
& \underline{\mathrm{d} \partial_{\mathrm{I}}}=\Delta \omega_{\mathrm{i}} \mathrm{i}=1, \ldots ., \mathrm{m} \\
& \mathrm{dt} \\
& \underset{\mathrm{d} \Delta \omega_{\mathrm{i}}}{\mathrm{dt}}={\underline{\pi \mathrm{f}_{\mathrm{o}}}}_{\mathrm{H}_{\mathrm{i}}}\left(\mathrm{P}_{\mathrm{m}}-\mathrm{P}_{\mathrm{e}}\right)
\end{aligned}
$$

We have two state equations for each generator, with initial power angel $\partial_{0}$, and $\Delta \omega \mathrm{O}_{i}=0$. The MATLAB function ode23 is employed to solve the above $2 \mathrm{~m}$ first order differential equations. When the fault if cleared, which may involve the removal of the faulty line, the bust admittance matrix is recomputed to reflect the change in the network. Next, the post-fault electrical power of the ith generator shown by $\mathrm{P}_{\mathrm{i}}^{\mathrm{f}}$ is readily determined. Using the post-fault power $\mathrm{P}^{\mathrm{pf}}{ }_{\mathrm{i}}$, the simulation is continued to determined the system stability, until the plot reveal a definite trend as to stability or instability. Usually, the slack generator is selected as the reference, and the phase angle difference of all other generators with respect to the reference machine are plotted. Usually, the solution is carried out for two swings to show that the second swing is not greater than the first one. If the angle differences increases indefinitely, the system is unstable.

\section{Case Study Question}

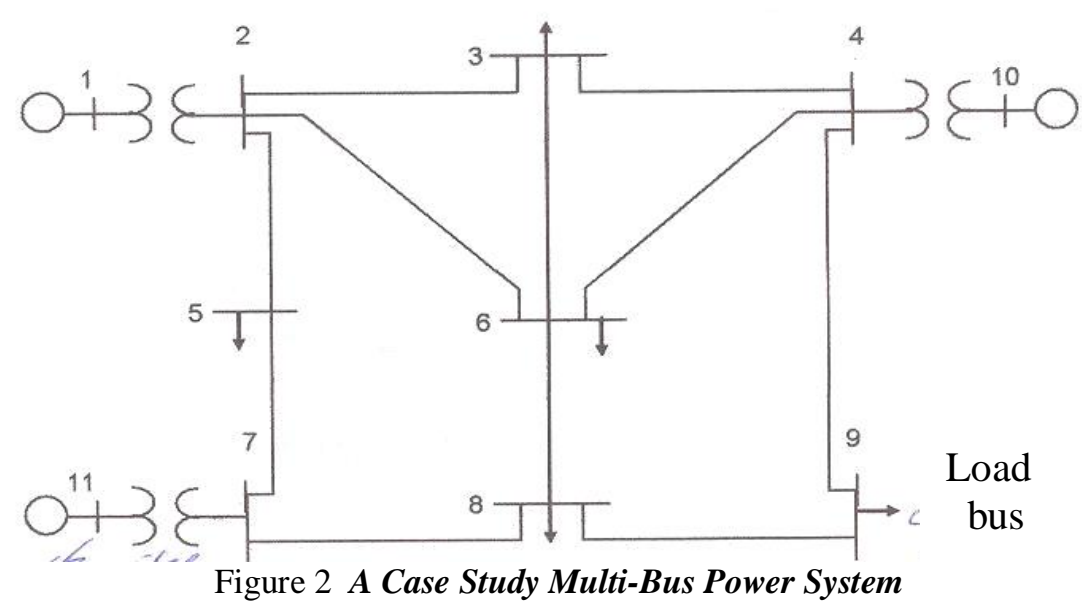




\begin{tabular}{|c|c|c|c|c|c|}
\hline \multicolumn{6}{|c|}{ LOAD DATA } \\
\hline \multicolumn{3}{|c|}{ Bus No. Load } & \multirow[t]{2}{*}{ Bus No. } & \multicolumn{2}{|c|}{ Load } \\
\hline & MW & Mvar & & MW & Mvar \\
\hline 1 & 0.0 & 0.0 & 7 & 0.0 & 0.0 \\
\hline 2 & 0.0 & 0.0 & 8 & 110.0 & 90.0 \\
\hline 3 & 150.0 & 120.0 & 9 & 80.0 & 50.0 \\
\hline 4. & 0.0 & 0.0 & 10 & 0.0 & 0.0 \\
\hline 5 & 120.0 & 60.0 & 11 & 0.0 & 0.0 \\
\hline 6 & 140.0 & 90.0 & & & \\
\hline
\end{tabular}

Voltage magnitude, generation schedule, and the reactive power limits for the regulated buses are tabulated below. Bus 1, whose voltage is specified as $V_{1}=1.040^{0}$, is taken as the slack bus.

\begin{tabular}{|lllll|}
\hline \multicolumn{2}{|l|}{ GENERATION SCHEDULE } & & \\
\hline Bus & Voltage & Generation & \multicolumn{2}{l|}{ Mvar Limits } \\
\cline { 5 - 6 } No. & Mag & MW & Min & Max \\
\hline 1 & 1.040 & & & \\
10 & 1.035 & 200.0 & 0.0 & 180.0 \\
11 & 1.030 & 160.0 & 0.0 & 120.0 \\
\hline
\end{tabular}

\begin{tabular}{|llllc|}
\hline \multicolumn{5}{|l|}{ LINE AND TRANSFORMER DATA } \\
\hline Bus & Bus No. & $\boldsymbol{R}$, & $\boldsymbol{X}$, & $\mathbf{1}, \mathbf{B}$, \\
No & & $\mathbf{P U}$ & $\mathbf{P U}$ & $\mathbf{P U}$ \\
\hline 1 & 2 & 0.000 & 0.006 & 0.000 \\
2 & 3 & 0.008 & 0.030 & 0.004 \\
2 & 5 & 0.004 & 0.015 & 0.002 \\
2 & 6 & 0.014 & 0.045 & 0.005 \\
3 & 4 & 0.010 & 0.040 & 0.005 \\
3 & 6 & 0.004 & 0.040 & 0.005 \\
4 & 6 & 0.015 & 0.060 & 0.008 \\
4 & 9 & 0.018 & 0.070 & 0.009 \\
5 & 7 & 0.005 & 0.043 & 0.003 \\
6 & 8 & 0.006 & 0.048 & 0.000 \\
7 & 8 & 0.006 & 0.035 & 0.000 \\
7 & 11 & 0.000 & 0.010 & 0.000 \\
8 & 9 & 0.005 & 0.048 & 0.000 \\
\hline
\end{tabular}

The generator's armature resistance and transient reactances in per unit, and the inertia constants expressed on a 100-MVA base are given below.

\begin{tabular}{|llcc|}
\hline MACHINE DATA & & \\
Gen. & $R_{\alpha}$ & $X{ }_{\mathrm{d}}$ & $H$ \\
\hline 1 & 0 & 0.20 & 12 \\
10 & 0 & 0.15 & 10 \\
11 & 0 & 0.25 & 9 \\
\hline
\end{tabular}

A three-phase fault occurs on line 4-9, near bus 4 , and is cleared by the simultaneous opening of breakers at both ends of the line. Using the trstab program, perform a transient stability analysis. Determine the stability for

a) When the fault is cleared in 0.4 second

b) When the fault is cleared in 0.8 second

c) Repeat the simulation to determine the critical clearing time.

VIII. Simulations And Results

\%Investigation of Transient Stability of a Typical Multibus Power System basemva $=100$; accuracy $=0.0001$; maxiter $=4$;

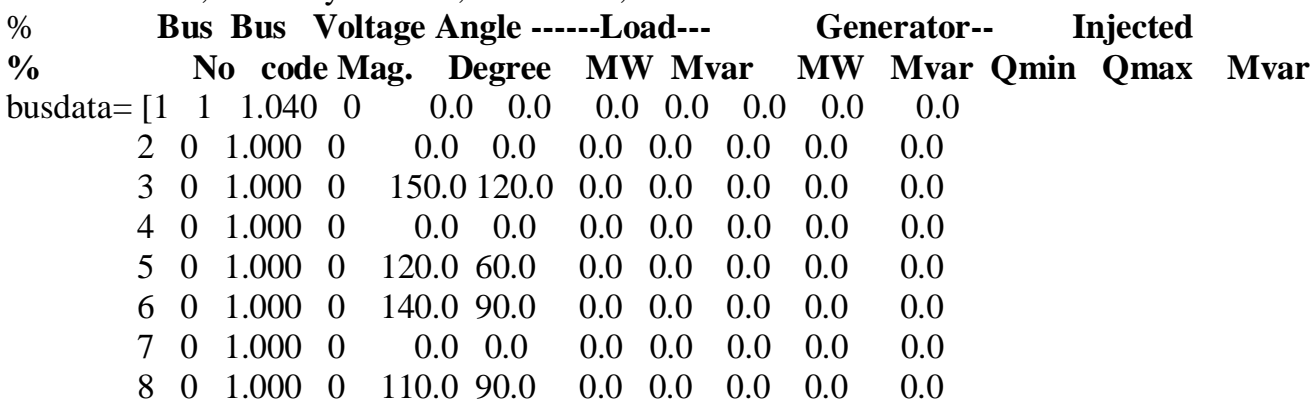




$\begin{array}{rrrrrrrrrrl}9 & 0 & 1.000 & 0 & 80.0 & 50.0 & 0.0 & 0.0 & 0.0 & 0.0 & 0.0 \\ 10 & 2 & 1.035 & 0 & 0.0 & 0.0 & 200.0 & 0.0 & 0.0 & 180.0 & 0.0 \\ 11 & 2 & 1.030 & 0 & 0.0 & 0.0 & 160.0 & 0.0 & 0.0 & 120.0 & 0.0] ;\end{array}$

$\%$ Line Data

$\begin{array}{lcccccc}\% & \text { Bus } & \text { Bus } & \mathrm{R} & \mathrm{X} & 1 / 2 \mathrm{~B} & \begin{array}{c}1 \text { for line code or } \\ \text { tap setting value }\end{array} \\ \% & \mathrm{nl} & \mathrm{nr} & \mathrm{pu} & \mathrm{pu} & \mathrm{pu} & \\ \text { linedata } & {[1} & 2 & 0.000 & 0.006 & 0.000 & 1.000 \\ & 2 & 3 & 0.008 & 0.030 & 0.004 & 1.000 \\ & 2 & 5 & 0.004 & 0.015 & 0.002 & 1.000 \\ & 2 & 6 & 0.012 & 0.045 & 0.005 & 1.000 \\ 3 & 4 & 0.010 & 0.040 & 0.005 & 1.000 \\ 3 & 6 & 0.004 & 0.040 & 0.005 & 1.000 \\ 4 & 6 & 0.015 & 0.060 & 0.008 & 1.000 \\ 4 & 9 & 0.018 & 0.070 & 0.009 & 1.000 \\ 4 & 10 & 0.000 & 0.008 & 0.000 & 1.000 \\ 5 & 7 & 0.005 & 0.043 & 0.003 & 1.000 \\ 6 & 8 & 0.006 & 0.048 & 0.000 & 1.000 \\ 7 & 8 & 0.006 & 0.035 & 0.004 & 1.000 \\ 7 & 11 & 0.000 & 0.010 & 0.000 & 1.000 \\ 8 & 9 & 0.005 & 0.048 & 0.000 & 1.000]\end{array}$

lfybus \%Forms the Bus Admittance Matrix

lfnewton \%Power Flow Solution by Newtons Raphson's Method busout \% Prints the Power Flow Solution on the screen

$\%$ Generator data

$\% \quad$ Gen. Ra Xd' H

gendata $=\left[\begin{array}{llll}1 & 0 & 0.20 & 12\end{array}\right.$

$\begin{array}{llll}10 & 0 & 0.15 & 10\end{array}$

$\left.\begin{array}{llll}11 & 0 & 0.25 & 9\end{array}\right]$

trstab \% Performs the Stability Analysis

\section{Results}

Power Flow Solution by Newton-Raphson Method

Maximum Power Mismatch $=1.35083 \mathrm{e}-009$

No. of Iterations $=4$

\begin{tabular}{|c|c|c|c|c|c|c|c|}
\hline \multirow[t]{2}{*}{ Bus } & \multicolumn{2}{|c|}{ Voltage Angle } & \multicolumn{2}{|c|}{------Load------ } & \multicolumn{2}{|c|}{---Generation--- } & \multirow{2}{*}{$\begin{array}{c}\text { Injected } \\
\text { Mvar }\end{array}$} \\
\hline & Mag. & Degre & MW & Mvar & MW & Mvar & \\
\hline 1 & 1.040 & 0.000 & 0.000 & 0.000 & 246.646 & 206.451 & 0.000 \\
\hline 2 & 1.028 & -0.793 & 0.000 & 0.000 & 0.000 & 0.000 & 0.000 \\
\hline 3 & 0.997 & -1.970 & 150.000 & 120.000 & 0.000 & 0.000 & 0.000 \\
\hline 4 & 1.024 & -0.608 & 0.000 & 0.000 & 0.000 & 0.000 & 0.000 \\
\hline 5 & 1.017 & -1.318 & 120.000 & 60.000 & 0.000 & 0.000 & 0.000 \\
\hline 6 & 0.993 & -2.277 & 140.000 & 90.000 & 0.000 & 0.000 & 0.000 \\
\hline 7 & 1.021 & -0.348 & 0.000 & 0.000 & 0.000 & 0.000 & 0.000 \\
\hline 8 & 0.985 & -2.414 & 110.000 & 90.000 & 0.000 & 0.000 & 0.000 \\
\hline 0 & 0.981 & -2.798 & 80.000 & 50.000 & 0.000 & 0.000 & 0.000 \\
\hline 10 & 1.035 & 0.257 & 0.000 & 0.000 & 200.000 & 141.499 & 0.000 \\
\hline 11 & 1.030 & 0.524 & 0.000 & 0.000 & 160.000 & 95.095 & 0.000 \\
\hline & & & & 00 & 646 & 5 & 0.000 \\
\hline
\end{tabular}

Prefault reduced bus admittance matrix

$\mathrm{Ybf}=$

$0.4044-3.5157 \mathrm{i} \quad 0.4006+1.2902 \mathrm{i} \quad 0.2718+0.8352 \mathrm{i}$ 


$$
\begin{array}{ccccc}
0.4006+1.2902 \mathrm{i} & 0.6446 & -3.9705 \mathrm{i} & 0.3069+0.9567 \mathrm{i} \\
0.2718+0.8352 \mathrm{i} & 0.3069+0.9567 \mathrm{i} & 0.2543-2.8759 \mathrm{i} \\
\mathrm{G}(\mathrm{i}) & \mathrm{E}^{\prime}(\mathrm{i}) & \mathrm{d} 0(\mathrm{i}) & \mathrm{Pm}(\mathrm{i}) & \\
1 & 1.5133 & 18.2666 & 2.4665 & \\
10 & 1.2735 & 13.4128 & 2.0000 & \\
11 & 1.3193 & 17.6434 & 1.6000 &
\end{array}
$$

Enter faulted bus No. -> 4

Faulted reduced bus admittance matrix

$$
\begin{aligned}
& \mathrm{Ydf}=
\end{aligned}
$$



Fault is cleared by opening a line. The bus to bus nos. of the line to be removed must be entered within brackets, e.g. [5, 7] Enter the bus to bus Nos. of line to be removed -> [4,9]

Postfault reduced bus admittance matrix

Yaf $=$

$$
\begin{array}{ccc}
0.4044-3.5200 \mathrm{i} & 0.3769+1.2857 \mathrm{i} & 0.2806+0.8320 \mathrm{i} \\
0.3769+1.2857 \mathrm{i} & 0.6195-3.8251 \mathrm{i} & 0.2897+0.8964 \mathrm{i} \\
0.2806+0.8320 \mathrm{i} & 0.2897+0.8964 \mathrm{i} & 0.2706-2.8569 \mathrm{i}
\end{array}
$$

Enter clearing time of fault in sec. $t c=0.4$

Enter final simulation time in sec. $\mathrm{tf}=1.5$

Fault is cleared at $0.400 \mathrm{Sec}$.

Phase angle difference of each machine with respect to the slack in degree.

$\begin{array}{ccc}\mathrm{t}-\mathrm{sec} & \mathrm{d}(10,1) & \mathrm{d}(11,1) \\ 0 & -4.8538 & -0.6232 \\ 0.0000 & -4.8538 & -0.6232 \\ 0.0000 & -4.8538 & -0.6232 \\ 0.0001 & -4.8538 & -0.6232 \\ 0.0003 & -4.8538 & -0.6232 \\ 0.0017 & -4.8532 & -0.6235 \\ 0.0083 & -4.8392 & -0.6315 \\ 0.0414 & -4.4886 & -0.8297 \\ 0.0814 & -3.4404 & -1.4131 \\ 0.1214 & -1.6994 & -2.3519 \\ 0.1614 & 0.7489 & -3.6117 \\ 0.2014 & 3.9239 & -5.1466 \\ 0.2414 & 7.8491 & -6.9005 \\ 0.2814 & 12.5509 & -8.8095 \\ 0.3214 & 18.0579 & -10.8041 \\ 0.3614 & 24.3994 & -12.8121 \\ 0.4000 & 31.3285 & -14.6926 \\ 0.4000 & 31.3285 & -14.6926 \\ 0.4172 & 34.0557 & -15.3637 \\ 0.4613 & 35.6987 & -15.6913 \\ 0.5078 & 29.1446 & -13.8943 \\ 0.5516 & 16.2204 & -10.3682 \\ 0.5897 & 1.4809 & -6.1724 \\ 0.6296 & -14.8352 & -1.1275 \\ 0.6639 & -27.4120 & 3.3285 \\ 0.6981 & -36.9246 & 7.5279 \\ 0.7329 & -42.2809 & 11.2161 \\ 0.7696 & -42.6082 & 14.2019 \\ 0.8096 & -36.7336 & 16.0783 \\ 0.8523 & -24.2747 & 16.1426\end{array}$




$\begin{array}{rrr}0.8986 & -6.2624 & 13.6123 \\ 0.9452 & 12.4112 & 8.3190 \\ 0.9987 & 28.6530 & -0.2903 \\ 1.0417 & 34.7078 & -7.9238 \\ 1.0870 & 33.1872 & -15.2398 \\ 1.1337 & 23.5992 & -20.5900 \\ 1.1801 & 7.9377 & -22.5060 \\ 1.2231 & -9.1656 & -20.6846 \\ 1.2741 & -27.8990 & -14.2372 \\ 1.3212 & -39.3503 & -5.3284 \\ 1.3590 & -42.5856 & 2.7592 \\ 1.3982 & -39.7683 & 11.0153 \\ 1.4403 & -30.2508 & 18.6414 \\ 1.4858 & -14.3039 & 24.1366 \\ 1.5000 & -8.6544 & 25.0590\end{array}$

Another clearing time of fault? Enter ' $y$ ' or ' $n$ ' within quotes -> 'y'

Enter clearing time of fault in sec. tc $=0.8$

Enter final simulation time in sec. $\mathrm{tf}=1.5$

Fault is cleared at $0.800 \mathrm{Sec}$.

Phase angle difference of each machine with respect to the slack in degree.

$\begin{array}{ccc}\mathrm{t}-\mathrm{sec} & \mathrm{d}(10,1) & \mathrm{d}(11,1) \\ 0 & -4.8538 & -0.6232 \\ 0.0000 & -4.8538 & -0.6232 \\ 0.0000 & -4.8538 & -0.6232 \\ 0.0001 & -4.8538 & -0.6232 \\ 0.0003 & -4.8538 & -0.6232 \\ 0.0017 & -4.8532 & -0.6235 \\ 0.0083 & -4.8392 & -0.6315 \\ 0.0414 & -4.4886 & -0.8297 \\ 0.1200 & -1.7772 & -2.3197 \\ 0.2000 & 3.7917 & -5.1002 \\ 0.2800 & 12.3631 & -8.7517 \\ 0.3600 & 24.1546 & -12.7462 \\ 0.4400 & 39.3973 & -16.5112 \\ 0.5200 & 58.3011 & -19.5146 \\ 0.6000 & 81.0276 & -21.3387 \\ 0.6800 & 107.6718 & -21.7339 \\ 0.7600 & 138.2535 & -20.6480 \\ 0.8000 & 155.0000 & -19.5933 \\ 0.8000 & 155.0000 & -19.5933 \\ 0.8319 & 168.5380 & -18.5285 \\ 0.9019 & 202.0733 & -15.4501 \\ 0.9612 & 244.5426 & -11.5951 \\ 0.9960 & 279.7510 & -8.3854 \\ 1.0307 & 322.6680 & -4.3362 \\ 1.0621 & 365.0544 & -0.2265 \\ 1.0993 & 413.6971 & 4.3950 \\ 1.1320 & 450.4586 & 7.4930 \\ 1.1655 & 481.0773 & 9.4097 \\ 1.2048 & 509.4997 & 10.0927 \\ 1.2573 & 540.5699 & 8.9470 \\ 1.3221 & 581.2444 & 5.5820 \\ 1.3616 & 614.5239 & 3.1352 \\ 1.4012 & 657.7771 & 0.7700 \\ 1.4361 & 703.1363 & -1.1357 \\ 1.4715 & 750.6554 & -2.9673 \\ 1.5000 & 785.9562 & -4.5066 \\ & & \end{array}$


Another clearing time of fault? Enter ' $y$ ' or ' $n$ ' within quotes -> ' $y$ '

Enter clearing time of fault in sec. tc $=0.72$

Enter final simulation time in sec. $\mathrm{tf}=1.5$

Fault is cleared at $0.720 \mathrm{Sec}$.

Phase angle difference of each machine

with respect to the slack in degree.

$\begin{array}{ccc}\mathrm{t}-\mathrm{sec} & \mathrm{d}(10,1) & \mathrm{d}(11,1) \\ 0 & -4.8538 & -0.6232 \\ 0.0000 & -4.8538 & -0.6232 \\ 0.0000 & -4.8538 & -0.6232 \\ 0.0001 & -4.8538 & -0.6232 \\ 0.0003 & -4.8538 & -0.6232 \\ 0.0017 & -4.8532 & -0.6235 \\ 0.0083 & -4.8392 & -0.6315 \\ 0.0414 & -4.4886 & -0.8297 \\ 0.1134 & -2.1058 & -2.1421 \\ 0.1854 & 2.5617 & -4.5116 \\ 0.2574 & 9.6312 & -7.6584 \\ 0.3294 & 19.2560 & -11.2129 \\ 0.4014 & 31.6047 & -14.7600 \\ 0.4734 & 46.8406 & -17.8904 \\ 0.5454 & 65.1028 & -20.2473 \\ 0.6174 & 86.4930 & -21.5661 \\ 0.6894 & 111.0668 & -21.7008 \\ 0.7200 & 122.4592 & -21.3941 \\ 0.7200 & 122.4592 & -21.3941 \\ 0.7490 & 132.0129 & -20.8527 \\ 0.8124 & 144.5639 & -18.8413 \\ 0.8834 & 148.4052 & -15.7092 \\ 0.9548 & 142.4651 & -12.1490 \\ 1.0171 & 126.2627 & -9.1812 \\ 1.0728 & 98.0077 & -6.9748 \\ 1.1068 & 72.1344 & -5.8896 \\ 1.1408 & 39.4201 & -4.9294 \\ 1.1695 & 7.7903 & -4.0881 \\ 1.1984 & -25.0585 & -3.0807 \\ 1.2277 & -56.3896 & -1.8027 \\ 1.2571 & -83.2976 & -0.2580 \\ 1.2866 & -104.7644 & 1.5049 \\ 1.3216 & -122.8326 & 3.7300 \\ 1.3720 & -136.4591 & 6.8719 \\ 1.4457 & -134.2779 & 10.6529 \\ 1.5000 & -115.2686 & 12.5815\end{array}$

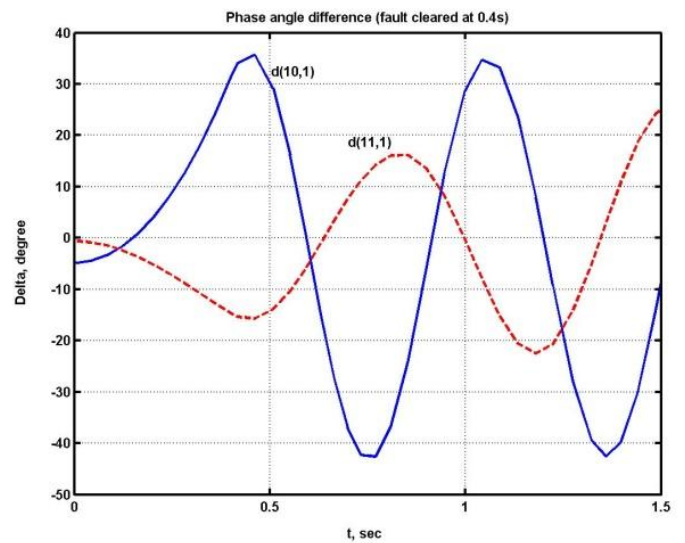

fig. 3.2 Phase angle difference (fault cleared at $0.4 \mathrm{~s}$ ) 


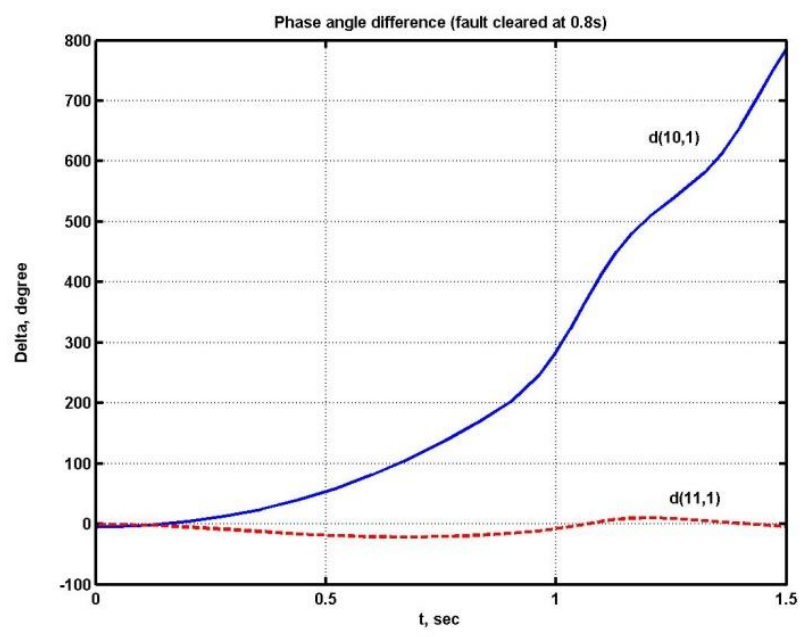

fig 3.3 Phase angle difference (fault cleared at $0.8 \mathrm{sec}$ )

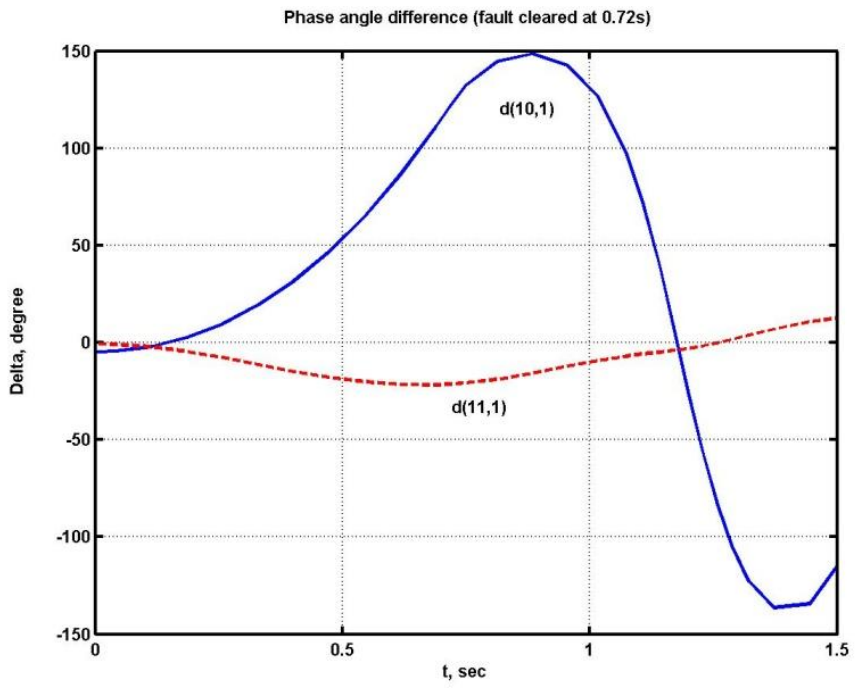

fig. 3.4: Phase angle difference (fault cleared at 0.72s)

\section{Conclusion}

The stability problem is concerned with the behaviour of the synchronous machines after a disturbance. Steady-state stability, transient stability, and dynamic stability conditions studies are needed to ensure that the power system can withstand any of the above conditions following a disturbance. Frequency, transient studies are conducted when new generating and transmitting facilities are planned. The studies are helpful in determining such things as the nature of the relaying system needed, critical clearing time of circuit breakers, voltage level of, and transfer capability between systems.

However, all physical systems are nonlinear to some extent. in order to use the transfer function and lower state equations, the system must first be linearized. Thus, proper assumptions and approximations are made so that a linear mathematical model can characterize the system. The model may be validated by analyzing its performance for realistic input conditions and then by comparing with field test data taken from dynamic system in its operating environment. Further analysis of the simulated model is usually necessary to obtain the model response for different feedback configuration and parameters settings. Once an acceptable controller as been designed and tested on the model, the feedback control strategy is then applied to the actual system.

Therefore, the MATLAB program is used with ease to simulate the nonlinear differential equations of the synchronous machines directly in time-domain in matrix form for all modes of operation. Thus, with the aid of MATLAB program, a designer and planner of generating and transmitting power station, sub-station etc. can observe the dynamic response of the synchronous machine during short-circuit and appreciate the significance and consequences of the change of machine parameter. The ultimate objective of MATLAB application in 
power system analysis is, to develop simple network model of the synchronous generator for power system fault analysis and transient stability conditions.

Thus, it aids in determining such things like the nature of relaying system needed, critical clearing time of circuit breakers, voltage level of, and transfer capability between system before planting any power station or substation and in day-to-day running of power stations. This is achieved through simulations and critical observations of the nature of the swing curves.

\section{References}

[1] A.A. Found and Vijay Vittal. (1992). Power System Transient Stability Analysis, New Jersey: Prentice Hall

[2] Allan Greenwood. (1987). Electrical Transients in Power System. New York. John Wiley and Sons.

[3] Edward Wilson Kimbark, Sc.D. (1964). Power System Stability. New York: John Wiley and Sons, Inc.

[4] J.E.L. Robinson. (1963). Abnormal Load on Power System. London Unwun Brothers Limited.

[5] Hadi Saadat. (2002). Power System Analysis. New Delhi: McGraw-Hill.

[6] M.G. Say. (1963). The Performance and Design of Alternating Current Machines. London: Sir Isaac Pitman and Sons Ltd.

[7] Richard T. Byerly. (1974). Stability of Large Electric Power System. New York. IEEE Press Inc. Vol 10 Pp. $220-222$.

[8] William D. Stevenson, Jr. (1962). Element of Power System Analysis. New York: McGraw-Hill Book Company, Inc. 